\title{
Procurement management of strategic inputs in coping with COVID-19: scoping
}

\section{review protocol}

\author{
Gestão de compras de insumos estratégicos no enfrentamento da COVID-19: protocolo de revisão \\ de escopo
}

Gestión de compras de insumos estratégicos para hacer frente a la COVID-19: protocolo de revisión de alcance

Received: 01/27/2022 | Reviewed: 02/01/2022 | Accept: 02/05/2022 | Published: 02/10/2022

\author{
Rondineli Mendes da Silva \\ ORCID: https://orcid.org/0000-0002-6243-5179 \\ Oswaldo Cruz Foundation, Brazil \\ E-mail: rondineli.mendes@gmail.com \\ Rosangela Caetano \\ ORCID: https://orcid.org/0000-0003-1480-2453 \\ State University of Rio de Janeiro, Brazil \\ E-mail: caetano.r@gmail.com \\ Vera Lucia Luiza \\ ORCID: https://orcid.org/0000-0001-6245-7522 \\ Oswaldo Cruz Foundation, Brazil \\ E-mail: negritudesenior@gmail.com \\ Daniela Moulin Maciel de Vasconcelos \\ ORCID: https://orcid.org/0000-0002-2710-7081 \\ Oswaldo Cruz Foundation, Brazil \\ E-mail: danielamoulin@gmail.com \\ Luisa Arueira Chaves \\ ORCID: https://orcid.org/0000-0002-9597-3651 \\ Federal University of Rio de Janeiro, Brazil \\ E-mail: luisa.arueira@gmail.com \\ Leandro Oliveira Paranhos \\ ORCID: https://orcid.org/0000-0002-9281-4743 \\ Niterói Municipal Health Secretariat, Brazil \\ E-mail: leandrooliveiraparanhos@gmail.com \\ Angelúcia Muniz \\ ORCID: https://orcid.org/0000-0002-1962-4396 \\ Federal University of Rio de Janeiro, Brazil \\ Oswaldo Cruz Foundation, Brazil \\ E-mail: munizangel@gmail.com \\ Claudia Garcia Serpa Osorio-de-Castro \\ ORCID: http://orcid.org/0000-0003-4875-7216 \\ Oswaldo Cruz Foundation, Brazil \\ E-mail: claudiaosorio.soc@gmail.com
}

\begin{abstract}
The health crisis triggered by the COVID-19 pandemic has challenged public management in several countries to ensure the timely and efficient procurement of the various health technologies necessary to cope with it, such as medicines, diagnostic tests, personal protective equipment (PPE) and medical materials/equipment, among others. This article introduces a protocol for a scoping review that aims to map and synthesize studies portraying the management capacity related to public procurement of inputs used in coping with the crisis arising from COVID-19. The protocol is intended to document the processes involved in the methodological planning and execution of a scoping review guided by Joanna Briggs Institute guidelines and developed using the 2015 PRISMA-Protocols (PRISMA-P) checklist. The PCC strategy (population, concept and context) systematized the search for studies published in MEDLINE, LILACS, Scopus, Embase, Web of Science and WHO-COVID-19 (Global literature on coronavirus disease), as well as in the gray literature, by September 2021. The selection of articles will be carried out in two steps (titles and abstracts, followed by the assessment of the full text of the articles), by two independent reviewers, with the resolution of disagreements by a third reviewer. The results will be analyzed qualitatively/quantitatively and will be organized by themes. The checklist present in the Preferred Reporting Items for Systematic Reviews and Meta-Analysis extension for Scoping Reviews (PRISMA-ScR) will be used to guide the
\end{abstract}


final review report. The protocol was registered in the Open Science Framework under the number 10.17605/OSF.IO/W6KHY.

Keywords: Biomedical technology; Public procurement; Scoping review; COVID 19.

\section{Resumo}

A crise sanitária desencadeada pela pandemia pela COVID-19 tem desafiado a gestão pública de diversos países para garantir a aquisição oportuna e eficiente das várias tecnologias de saúde necessárias ao seu combate, como medicamentos, testes diagnósticos, equipamentos de proteção individual (EPI) e materiais/equipamentos médicos, dentre outros. O artigo apresenta um protocolo de uma revisão de escopo que objetiva mapear e sintetizar estudos que retratem a capacidade de gestão relacionada às compras públicas de insumos empregados no enfrentamento decorrente da COVID-19. O protocolo destina-se a documentar os processos envolvidos no planejamento metodológico e execução de uma revisão de escopo orientada pelas diretrizes do Joanna Briggs Institute e desenvolvido usando a checklist do PRISMA-Protocols (PRISMA-P) 2015. A estratégia PCC (população, conceito e contexto) sistematizou a busca por estudos publicados nas bases bibliográficas MEDLINE, LILACS, Scopus, Embase, Web of Science e WHO-COVID-19 (Global literature on coronavírus disease), bem como na literatura cinzenta, até setembro de 2021. A seleção dos artigos será realizada em duas etapas (títulos e resumos, seguida da avaliação do texto completo dos artigos), por dois avaliadores independentes, com resolução das divergências por um terceiro revisor. Os resultados serão analisados qualiquantitativamente e serão organizados por temas. O checklist presente no Preferred Reporting Items for Systematic Reviews and Meta-Analysis extension for Scoping Reviews (PRISMA-ScR) será utilizado para orientar o relatório final da revisão. O protocolo foi registrado no Open Science Framework sob o número 10.17605/OSF.IO/W6KHY.

Palavras-chave: Tecnologias em saúde; Compras públicas; Revisão de escopo; COVID 19.

\section{Resumen}

La crisis sanitaria desencadenada por la pandemia del COVID-19 ha desafiado a la gestión pública en varios países para asegurar la adquisición oportuna y eficiente de las diversas tecnologías sanitarias necesarias para hacerle frente, como medicamentos, pruebas diagnósticas, equipos de protección personal (EPP) y materiales/equipos médicos entre otros. Este artículo presenta un protocolo para una revisión de alcance que tiene como objetivo mapear y sintetizar estudios que retraten la capacidad de gestión relacionada con la contratación pública de insumos utilizados para enfrentar la crisis derivada de COVID-19. El protocolo tiene como objetivo documentar los procesos involucrados en la planificación metodológica y la ejecución de una revisión de alcance guiada por las pautas del Instituto Joanna Briggs y desarrollada utilizando la lista de verificación PRISMA-Protocols (PRISMA-P) de 2015. La estrategia PCC (población, concepto y contexto) sistematizó la búsqueda de estudios publicados en MEDLINE, LILACS, Scopus, Embase, Web of Science y OMS-COVID-19 (literatura global sobre enfermedad por coronavirus), así como en la literatura gris, hasta septiembre de 2021. La selección de artículos se realizará en dos pasos (títulos y resúmenes, seguido de la evaluación del texto completo de los artículos), por dos revisores independientes, con la resolución de desacuerdos por un tercer revisor. Los resultados se analizarán cualitativa/cuantitativamente y se organizarán por temas. La lista de verificación presente en Preferred Reporting Items for Systematic Reviews and Meta-Analysis extension for Scoping Reviews (PRISMA-ScR) se utilizará para guiar el informe de revisión final. El protocolo se registró en Open Science Framework con el número 10.17605/OSF.IO/W6KHY.

Palabras clave: Tecnología biomédica; Compras publicas; Revisión de alcance; COVID 19.

\section{Introduction}

Due to the spread of the new Coronavirus in several countries, the World Health Organization (WHO) declared a public health emergency of international importance on January $30^{\text {th }}, 2020$; and, subsequently, on March $11^{\text {th }}$, 2020, declared a pandemic situation in which refers to infection by the etiologic agent SARS-CoV-2 (Alves et al., 2020). In Brazil, the first case of COVID-19 was identified on February $26^{\text {th }}, 2020$, in São Paulo and, less than a month after its confirmation, all Brazilian states had already reported cases of the disease, with deaths recorded in eight of them (Silva et al., 2020). Since then, the number of cases in the country has exceeded 21 million, with more than 610,000 deaths (World Health Organization, 2021).

Given the emergency situation resulting from the global crisis, an adverse, uncertain and complex scenario was established that challenged the public management of several countries to ensure the efficient procurement of health technologies during the fight against the pandemic, which involves medicines, diagnostic tests, personal protective equipment (PPE) and medical materials/equipment, among others. Thus, in addition to the various activities in the health area, which 
include preventive measures, diagnosis and assistance to patients affected by the disease, other actions are imbricated, such as public procurement management and the supply chain of these strategic inputs.

Public procurement is understood as the process by which governments seek to obtain services, materials and equipment necessary for their functioning in compliance with the laws in force, encompassing the provision of public goods and services freely available to the population such as health, safety, education and infrastructure (Schmidt et al., 2011; Thai, 2001). The development of management actions on public procurement is not a trivial task, because it depends on a succession of chained steps, requiring from the buyer a broad view of the health context, in addition to more specific knowledge, linked to the administrative, legal, economic and technical dimensions. Such aspects provide greater agility in the procurement process, the achievement of competitive prices and the guarantee of the quality of the products to be purchased (Osorio-de-Castro et al., 2014).

Public sector procurement is central to adequately responding to crisis situations, such as the new coronavirus pandemic, and requires governments to have the ability to select and assemble the necessary materials at short notice to trigger effective delivery of government services (Atkinson et al., 2020). In this context, the purchase may run into difficulties, in view of the increase in demand, the low availability of raw materials of manufacturing inputs and finished products, besides the increase in prices (Amaya et al., 2021; Gaudette, 2020).

Despite being a strategic aspect for the success of health actions, the theme related to administrative management is little debated in the scientific literature and has often received more attention when there are reports of shortages (Cohen \& Rodgers, 2020), corruption (Teremetskyi et al., 2021), etc. In the current context of the health emergency, it is proposed to investigate the key characteristics and challenges imposed on the public procurement management of health technologies as part of the formulation of responses to COVID-19 through a scoping review.

This paper represents the scoping review planning protocol to map and synthesize studies published in the scientific and gray literature portraying management capacity related to public procurement of medicines, diagnostic tests, medical materials/equipment and PPE used in coping with the crisis arising from COVID-19.

\section{Methods}

\subsection{Study design}

The scoping review allows for a broad exploration of the theme under investigation, in this case, the management of strategic supplies procurement in the context of meeting the demands generated by COVID-19. This type of review makes it possible to identify thematic, bibliometric, conceptual and organizational aspects (Arksey et al., 2005a).

Scoping reviews have great utility and are often used to map the existing literature in a particular field in terms of its nature, characteristics, key concepts and volume (Arksey et al., 2005b). They are commonly used for recognition, that is, to clarify the working definitions and conceptual boundaries of a topic or field (Anderson et al., 2008; Ehrich et al., 2002). It is a method that is considered consistent to show the results in an accessible format, through a rigorous and systematic approach.

The choice for this type of review when compared to other possibilities, such as the systematic review, is justified because the research question is comprehensive, with a more exploratory nature, aiming to apprehend a larger contingent of studies related to the theme, added to the expectation of the existence of studies with diverse methodological designs (Morris, MSc et al., 2017). Scoping reviews can be conducted to determine the value of a full systematic review, and also as independent exercises to summarize and disseminate research findings, to identify research gaps and to make recommendations for future research (Nyanchoka et al., 2019). 
In this circumstance, themes related to COVID-19, a new disease and, specifically, the management of purchases related to its combat, are still marked by uncertainty and heterogeneity. Therefore, it is a research theme that is still little studied.

In a survey carried out in August 2021 on the Open Science Framework (OSF) platform and on the international PROSPERO database (International Prospective Register of Systematic Reviews), which allow the registration of scoping review protocols, no scoping or systematic review was identified in progress or published related to the proposed theme.

This scoping review will follow the methodology for this type of review proposed by the Joanna Briggs Institute (Aromataris et al., 2020), using the Preferred Reporting Items for Systematic Reviews and Meta-Analysis extension for Scoping Reviews checklist (PRISMA-ScR) (Tricco et al., 2018). This review protocol was structured based on the 2015 Preferred Reporting Items for Systematic Review and Meta-Analysis Protocols checklist (PRISMA-P) (Shamseer et al., 2015).

\subsection{Research guiding questions}

The scoping review will involve research on public procurement. A few questions structure the conduct of the research as well as the conduct of the analyses on the key concepts and evidence identified in the proposed scoping review:

1. What are the key characteristics involved in the procurement of medicines, diagnostic tests, PPE and medical materials/equipment for coping with COVID-19 present in the scientific and gray literature?

2. What challenges were identified and what strategies were used to deal with the difficulties faced?

The research question or scoping review question guides and directs the development of the specific inclusion criteria. In addition, its clarity aids in the development of the protocol, facilitates the conduct of the literature search and provides a clear framework for the development of the scoping review (Aromataris et al., 2020).

The mnemonic PCC, Population, Concept and Context is recommended for constructing the scoping review, and should be incorporated into both the title and the structuring of the question (Table 1).

Table 1. Population, Concept and Context of the proposed scoping review.

\begin{tabular}{|l|l|}
\hline Criteria & Description \\
\hline Population & Medicines, diagnostic tests, personal protective equipment, materials and medical equipment \\
\hline Concept & Procurement management \\
\hline Context & COVID-19 pandemic \\
\hline
\end{tabular}

Source: Authors,

\subsection{Search for relevant studies}

The search strategy to identify published studies addressing health technology procurement in the fight against COVID-19 took place collaboratively and was supported by an experienced librarian from the Oswaldo Cruz Foundation.

The following databases were searched: MEDLINE (via PubMed), Latin American and Caribbean Health Sciences Literature (LILACS), Embase, Scopus, Web of Science and WHO (COVID-19. Global literature on coronavirus disease). All searches were performed on August 27th and 28th, 2021.

The time frame covered was January/2019, up to the date of the searches, which thus covers approximately 16 months since the declaration of the pandemic caused by the new coronavirus.

The search strategy was broad and adapted according to the syntax to be performed in each base, covering the theme by using descriptors in health sciences (DeCS, MeSH or Emtree), when available, and free words in the title, abstract and text 
of the manuscripts, involving three major cores: (a) procurement management; (b) strategic inputs (medicines, diagnostic tests, personal and collective protection equipment, medical materials and equipment); and (c) COVID-19. The search was restricted to human studies and adapted according to the syntax for each base (Table 2).

Table 2: General structure of the terms and search strategy used according to the cores involved in the scoping review.

\begin{tabular}{|l|l|}
\hline \multicolumn{1}{|c|}{ Core terms } & \multicolumn{1}{|c|}{ General structure (adapted according to database) } \\
\hline $\begin{array}{l}\text { Management, Procurement, } \\
\text { Purchasing }\end{array}$ & $\begin{array}{l}\text { (Procurement OR "Purchasing, Hospital" OR "Hospital Purchasing" OR Budget OR } \\
\text { "management purchasing" OR purchasing*) }\end{array}$ \\
\hline $\begin{array}{l}\text { Medicines, diagnostic tests, personal } \\
\text { protective equipment, materials and } \\
\text { medical equipment }\end{array}$ & $\begin{array}{l}\text { ("Diagnostic Test Approval" OR "Chain Supply" OR "supply Chain" OR "Equipment } \\
\text { and Supplies" OR "Medical devices" OR Medicines OR Drugs OR "Pharmaceutical } \\
\text { Preparations" OR "Personal Protective Equipment" OR "PPI") }\end{array}$ \\
\hline Covid-19 & $\begin{array}{l}\text { ("New Coronavirus" OR "Novel Coronavirus" OR "Nuevo Coronavirus" OR "Novo } \\
\text { Coronavirus" OR "Coronavirus disease" OR "Enfermedad por Coronavirus" OR } \\
\text { "2019-nCoV" OR "COVID19" OR "COVID-19" OR "COVID2019" OR "COVID- } \\
\text { 2019" OR "COVID 2019" OR "SRAG-CoV-2" OR "SARS2" OR "SARS-CoV-2" } \\
\text { OR "Coronavirus") }\end{array}$ \\
\hline
\end{tabular}

Source: Authors.

By means of cross-search in the articles initially selected, additional references will be searched, seeking to identify other potential articles related to the theme and to increase the coverage of the research carried out.

A search for gray literature was also carried out, in research sources defined by convenience. This option is justified by the fact that the theme of COVID-19 is still emerging, involving a set of investigation specificities and recent coping actions, with the participation of several national and international organizations recognized around the world that contributed to the publication of reports and documents that may be related to the theme under examination.

In addition to the OpenGrey multidisciplinary database, other international sources researched included the World Health Organization (WHO), the Pan American Health Organization (PAHO), the Organization for Economic Co-operation and Development (OECD) and the European Union (EU). The national sources involved the websites of the Brazilian Ministry of Health (MS), the National Council of Health Secretaries (CONASS), the National Council of Municipal Health Secretaries (CONASEMS) and the Institute for Applied Economic Research (Ipea).

The gray literature searches were performed separately and manually on each of the websites of the aforementioned organizations. Words (and combinations) of the terms "COVID-19", "novocoronavírus", "compras", "procurement", "purchasing", "supply chain" were used in this step.

The search strategies applied in each of the bases listed in the scientific and gray literature, with the respective amount of retrieved references, are displayed in Table 3. 
Table 3. Search strategies and quantity of retrieved papers.

Scientific literature

Database

""purchasings"'"[Title/Abstract] OR (""chain supply"'[Title/Abstract] OR ""chain supplying""[Title/Abstract])) AND ("'diagnostic test

approval""[MeSH Terms] OR ("'diagnostic test approval""[Title/Abstract] OR "'diagnostic test approvals"'[Title/Abstract]) OR ""equipment and supplies""[Title/Abstract] OR "'equipment and supplies"'"[MeSH Terms] OR "'medical devices"'"[Title/Abstract] OR ""pharmaceutical preparations""[Title/Abstract] OR ""pharmaceutical preparations""[MeSH Terms] OR ""drugs""[Title/Abstract] OR ""medicines""'[Title/Abstract] OR ("'personal protective equipment""[Title/Abstract] OR "'personal protective equipments"'[Title/Abstract]) OR ""personal protective equipment""[MeSH Terms] OR "'ppe""[Title/Abstract]) AND ("'new coronavirus""'[Title/Abstract] OR "'coronavirus disease""[Title/Abstract] OR ""2019 ncov""'[Title/Abstract] OR ""covid19"'"[Title/Abstract] OR ""covid2019"'"[Title/Abstract] OR "'sars cov 2""[Title/Abstract] OR "'betacoronavirus""'[MeSH Terms])"

WHO (COVID-19) (tw: ( (budget OR "Procurement" OR "Purchasing, Hospital" OR "Hospital Purchasing" OR "management purchasing" OR purchasing*))) AND (tw:(("Diagnostic Test Approval" OR "Equipment and Supplies" OR "Medical devices" OR medicines OR drugs OR "Pharmaceutical Preparations" OR "Personal Protective Equipment" )))

Embase $\quad$ (('diagnostic test approval':ti,ab,kw OR 'chain supply':ti,ab,kw OR 'supply chain':ti,ab,kw OR equipment:ti,ab,kw) AND supplies:ti,ab,kw OR 'medical devices':ti,ab,kw OR medicines:ti,ab,kw OR drugs:ti,ab,kw OR 'pharmaceutical preparations':ti,ab,kw OR 'personal protective equipment':ti,ab,kw OR 'personal protective equipment':ti,ab,kw OR 'ppi':ti,ab,kw) AND ('new coronavirus':ti,ab,kw OR 'novel coronavirus':ti,ab,kw OR 'nuevo coronavirus':ti,ab,kw OR 'novo coronavirus':ti,ab,kw OR 'coronavirus disease':ti,ab,kw OR 'enfermedad por coronavirus':ti,ab,kw OR '2019-ncov':ti,ab,kw OR 'covid19':ti,ab,kw OR 'covid-19':ti,ab,kw OR 'covid2019':ti,ab,kw OR 'covid-2019':ti,ab,kw OR 'covid 2019':ti,ab,kw OR 'srag-cov-2':ti,ab,kw OR 'sars2':ti,ab,kw OR 'sars-cov-2':ti,ab,kw OR 'coronavirus':ti,ab,kw) AND (procurement:ti,ab,kw OR 'purchasing, hospital':ti,ab,kw OR 'hospital purchasings':ti,ab,kw OR budget:ti,ab,kw OR 'management purchasings':ti,ab,kw OR purchasing*:ti,ab,kw) (TITLE-ABS-KEY ( "Diagnostic Test Approval" OR "Chain Supply" OR "supply Chain" OR "Equipment and Supplies" OR "Medical devices" OR medicines OR drugs OR "Pharmaceutical Preparations" OR "Personal Protective Equipment" OR "Personal Protective Equipment" OR "PPI" ) AND TITLE-ABS-KEY ( "New Coronavirus" OR "Novel Coronavirus" OR "Nuevo Coronavirus" OR "Novo Coronavirus" OR "Coronavirus disease" OR "Enfermedad por Coronavirus" OR "2019-nCoV" OR "COVID19" OR "COVID-19" OR "COVID2019" OR "COVID-2019" OR "COVID 2019" OR "SRAG-CoV-2" OR "SARS2" OR "SARS-CoV-2" OR "Coronavirus" ) AND TITLE-ABS-KEY (procurement OR "Purchasing, Hospital" OR "Hospital Purchasing" OR budget OR "management purchasing" OR purchasing*)) (purchasing*)) OR ("Supply chain")) OR ("chain supply"))) AND (TS=((((((("Diagnostic Test Approval") OR ("Equipment and Supplies")) OR ("Medical devices")) OR (medicines)) OR (drugs)) OR ("Pharmaceutical Preparations")) OR ("Personal Protective Equipment")))) AND (TS=((()((()(((()((("New Coronavirus") OR ("Novel Coronavirus")) OR ("Nuevo Coronavirus")) OR ("Novo Coronavirus")) OR ("Coronavirus disease")) OR ("Enfermedad por Coronavirus")) OR ("2019-nCoV")) OR ("COVID19")) OR ("COVID-19")) OR ("COVID2019")) OR ("COVID2019")) OR ("COVID 2019")) OR ("SRAG-CoV-2")) OR ("SARS2")) OR ("SARS-CoV-2")) OR ("Coronavirus"))) 
OR "Pharmaceutical Preparations" OR "Personal Protective Equipment" OR "Personal Protective Equipment" OR "PPI") AND ("New Coronavirus" OR "Novel Coronavirus" OR "Nuevo Coronavirus" OR "Novo Coronavirus" OR "Coronavirus disease" OR "Enfermedad por Coronavirus" OR "2019-nCoV" OR "COVID19" OR "COVID-19" OR "COVID2019" OR "COVID-2019" OR "COVID 2019" OR "SRAG-CoV-2" OR "SARS2" OR

"SARS-CoV-2" OR "Coronavirus") AND (Procurement OR "Purchasing, Hospital" OR "Hospital Purchasing" OR Budget OR "management purchasing" OR purchasing*)

\section{Grey literature \\ Open Grey}

WHO

OECD

$\mathrm{EU}$

PAHO

IPEA

MS

Conass

CONASEMS (coronavirus OR covid OR covid-19) AND procurement

Manual search

Procurement AND (COVID-19 OR "new coronavirus")

Procurement AND (COVID-19 OR "new coronavirus")

Manual search

COVID-19 AND procurement

Manual search

Manual search

Manual search

Source: Authors. 


\subsection{Manuscript selection based on inclusion and exclusion criteria}

This step will involve the application of inclusion and exclusion criteria, which are based on the specificities of the research question to select the relevant studies (Arksey et al., 2005b).

\subsubsection{Inclusion criteria}

Different types of works will be accepted, encompassing research articles, opinion articles, essays, reports, discussion papers and review articles published in academic journals, in English, Spanish and Portuguese, as of January 2019. It will include papers on procurement for public purposes or involving health care in the fight against COVID-19 and showing general characteristics, key concepts, organization of purchasing processes, in addition to approaches to problems and strategies related to procurement. Because of the advent of the pandemic, issues related to the supply chain and its management will be added, as these may involve procurement issues.

\subsubsection{Exclusion criteria}

Researches addressing specific themes that portray clinical studies of treatments, use and diagnosis, production of strategic inputs, management training, as well as treatment and diagnostic protocols, will be excluded.

Publications classified as letters, conference proceedings, book reviews, clinical trials, as well as academic works from doctoral theses and master's dissertations and conference presentations will also be excluded.

\subsubsection{Article selection process}

The bibliographic references identified through the search strategies will be exported and managed by the Zotero® software, in order to identify and eliminate duplications.

After removing the duplicates, the selection of articles will be carried out in two steps. The first will involve reading and analyzing titles and abstracts in line with the established inclusion criteria. The second step will involve obtaining and assessing the full text with the purpose of selecting only those that fully meet the eligibility criteria, as well as those whose relevance to the research is not clear only by the title/abstract, marked as doubt. Reasons for excluding studies after full text review will be documented.

Two independent reviewers will select the articles, with disagreements resolved by a third reviewer.

A spreadsheet will be structured in the Excel program, exported from the Zotero® software, in order to organize the extraction phase. The study selection process, which will involve the identification, selection and inclusion of articles, will be synthesized through a flow chart using the PRISMA model, which will contain the total of articles retrieved in the search, excluded duplicates, selected articles and, finally, those included in the scoping review.

\subsection{Data extraction}

Similar to the process to be carried out in the selection of articles, two reviewers independently will perform the data extraction of the articles included in this review. Cases of disagreement will be mediated by a third reviewer. 
From the library developed in the Zotero® software, a standardized electronic spreadsheet in the Excel ${ }^{\circledR}$ application will be generated for data extraction, to be previously tested by the reviewers in a set of included studies, with a view to determining if the approach and content is consistent with the question and the purpose of the research.

As in the previous steps, data extraction from the selected articles will be conducted independently by two reviewers, with an opinion issued by a third reviewer in case of disagreements.

The data to be extracted to guide the analysis are displayed in Table 4 .

Table 4. Items and sub-items for data extraction.

\begin{tabular}{|c|c|}
\hline \multicolumn{2}{|l|}{ Dimensions of scientific literature } \\
\hline $\begin{array}{l}\text { Geographic location and author } \\
\text { affiliations }\end{array}$ & $\begin{array}{l}\text { - Country where the study was developed } \\
\text { - Region/country where the study was published } \\
\text { - First author affiliations (by type) } \\
\text { - Journal's name } \\
\text { - Funding source }\end{array}$ \\
\hline General characteristics of the study & $\begin{array}{l}\text { - Year of publication } \\
\text { - Object and objectives of the study } \\
\text { - Research approach/methodology }\end{array}$ \\
\hline Theme Grouping Categories & $\begin{array}{l}\text { - Type of technology studied } \\
\text { - Components of purchases involved (absence of suppliers, delivery } \\
\text { time, shortages, deadlines, failures with acquisitions) } \\
\text { - Purchase-related market dynamics } \\
\text { - Strategies: negotiation, centralization of purchases, regulatory } \\
\text { approaches, transparency, change in the legislative framework }\end{array}$ \\
\hline Results and conclusions & $\begin{array}{l}\text { - Main characteristics, problems and actions addressed for } \\
\text { procurements } \\
\text { - Research gaps/Limitations }\end{array}$ \\
\hline \multicolumn{2}{|l|}{ Dimensions of grey literature } \\
\hline Source & $\begin{array}{l}\text { - Source of international gray literature (WHO, OECD, WHO, } \\
\text { PAHO, EU) } \\
\text { - Source of national gray literature (MS, IPEA, Conass, Conasems) }\end{array}$ \\
\hline General characteristics of the study & $\begin{array}{l}\text { - Year of publication } \\
\text { - Publication type (report, working document, discussion document, } \\
\text { series) } \\
\text { - Main points addressed }\end{array}$ \\
\hline
\end{tabular}

\subsection{Methodological quality assessment}

There is considerable debate in the literature about the obligation to include assessment of the methodological quality of studies in scoping reviews, mainly because these aim to provide a broad spectrum of knowledge and types of evidence available on a topic, clarify important concepts and obtain a comprehensive understanding of new concepts (Khalil et al., 2016; Munn et al., 2018). In the current review, considering the scope and object of the intended purpose, no methodological quality assessment tool will be applied. 


\subsection{Analysis and summarization of results}

Given the advent of the pandemic, which is still recent, significant heterogeneity among studies is expected, especially in relation to methodologies. In this sense, many papers can be supported by experience reports, opinion articles, essays and descriptive studies on the reflexes and the fight against COVID-19, purchase of medicines, diagnostic tests, personal protective equipment and medical materials/equipment.

Data summarization will involve a quantitative component, which synthesizes the frequency using simple percentage and the main characteristics of the studies, and a qualitative component, to outline the underlying concepts/theories and the elements and structures of the conceptual models identified in the search.

Quantitative data will be displayed in the form of charts, tables and graphic elements. The qualitative analysis will be guided by the expositions and key points identified by the authors classified into categories defined from the reading of the articles, and then a narrative synthesis will be produced. In addition, a summary chart of each study will be made available as supplementary material to the scoping review study.

The final review report will follow that recommended in the checklist according to the Preferred Reporting Items for Systematic Reviews and Meta-Analysis extension for Scoping Reviews (PRISMA-ScR) (Tricco et al., 2018).

\section{Ethical aspects}

This protocol refers to a scoping review, having as sources of information published scientific studies or public documents with unrestricted access, which involve administrative data. Accordingly, prior ethical approval by ethics committees in research involving human subjects will not be necessary. Nevertheless, the authors of this review declare that they have no links with funding institutions that may characterize potential conflicts of interest and its results will be published in open access journals or presented in relevant scientific events.

\section{Final Considerations}

The existence of knowledge gaps as a result of the new disease and the need to implement, in a short period of time and with a high degree of uncertainty, intervention actions with levels of evidence of safety and effectiveness that are still uncertain, has demanded from health managers agility in the decision-making process. Such issues put a strain on governments to provide urgent measures to purchase health technologies that can support health care.

The COVID-19 pandemic has exposed the existing inadequacy of systems and the underlying processes and vulnerabilities in the supply chain of the globally established health care system, and especially in the procurement systems. Elements such as demand and supply stressed the supply systems, which are very dependent on a few countries, which concentrate the production of the health technologies addressed in the scoping review.

The relevance of the pandemic, associated with the importance of procurement management, has still been little addressed in studies, which is why a scoping review is justified. It was necessary to expand the search beyond the procurement issues, introducing elements of the supply chain, since these themes have a direct correlation with the object under study. 
Finally, the protocol for carrying out a scoping review aimed to systematize the succession of methodological paths classically established in the pertinent literature. It is expected that one of the findings compiled from this review will support the preparation of notes and guidelines for the field of management according to the Brazilian reality, which has a complex federative system, in addition to its continental dimension.

In addition, future research that seeks to identify issues related to public procurement of health technologies to address the Covid-19 pandemic may provide input on other public management challenges, given the scenario of uncertainties still present.

\section{Funding}

The research is funded under the Fiocruz Innovation Promotion Program (Inova Fiocruz) - Knowledge Generation - Coping with the Covid-19 Pandemic and Post-Pandemic.

\section{References}

Alves, H. J. de P., Fernandes, F. A., Lima, K. P. de, Batista, B. D. de O., \& Fernandes, T. J. (2020). A pandemia da COVID-19 no Brasil: Uma aplicação do método de clusterização k-means. Research, Society and Development, 9(10), e5829109059. https://doi.org/10.33448/rsdv9i10.9059

Amaya, A. B., \& De Lombaerde, P. (2021). Regional cooperation is essential to combatting health emergencies in the Global South. Globalization and Health, 17(1). Scopus. https://doi.org/10.1186/s12992-021-00659-7

Anderson, S., Allen, P., Peckham, S., \& Goodwin, N. (2008). Asking the right questions: Scoping studies in the commissioning of research on the organisation and delivery of health services. Health Research Policy and Systems, 6(1), 7. https://doi.org/10.1186/1478-4505-6-7

Arksey, H., \& O’Malley, L. (2005a). Scoping studies: Towards a methodological framework. International Journal of Social Research Methodology, 8(1), 19-32. https://doi.org/10.1080/1364557032000119616

Arksey, H., \& O’Malley, L. (2005b). Scoping studies: Towards a methodological framework. International Journal of Social Research Methodology, 8(1), 19-32. https://doi.org/10.1080/1364557032000119616

Aromataris, E., \& Munn, Z. (Editors). (2020). JBI Manual for Evidence Synthesis. JBI. https://doi.org/10.46658/JBIMES-20-01

Atkinson, C. L., McCue, C., Prier, E., \& Atkinson, A. M. (2020). Supply Chain Manipulation, Misrepresentation, and Magical Thinking During the COVID-19 Pandemic. American Review of Public Administration, 50(6-7), 628-634. https://doi.org/10.1177/0275074020942055

Cohen, J., \& Rodgers, Y. V. D. M. (2020). Contributing factors to personal protective equipment shortages during the COVID-19 pandemic. Preventive Medicine, 141 (106263). https://doi.org/10.1016/j.ypmed.2020.106263

Ehrich, K., \& Freeman, G. K. (2002). How to do a Scoping Exercise: Continuity of Care. Research Policy and Planning $20(1)$, $25-29$. Retrieved from http://ssrg.org.uk/wp-content/uploads/2012/02/rpp201/shortreport1.pdf

Gaudette, E. (2020). COVID-19's Limited Impact on Drug Shortages in Canada. Canadian Public Policy-Analyse De Politiques, 46, S307S312. https://doi.org/10.3138/cpp.2020-107

Khalil, H., Peters, M., Godfrey, C. M., McInerney, P., Soares, C. B., \& Parker, D. (2016). An evidence-based approach to scoping reviews. Worldviews on evidence-based nursing, 13(2), 118-123. https://doi.org/10.1111/wvn.12144

Morris, MSc, M., Boruff, MLIS, J. T., \& Gore, MLIS, G. C. (2017). Scoping reviews: Establishing the role of the librarian. Journal of the Medical Library Association, 104(4). https://doi.org/10.5195/JMLA.2016.156

Munn, Z., Peters, M. D. J., Stern, C., Tufanaru, C., McArthur, A., \& Aromataris, E. (2018). Systematic review or scoping review? Guidance for authors when choosing between a systematic or scoping review approach. BMC Medical Research Methodology, $18(1)$, 143 . https://doi.org/10.1186/s12874-018-0611-x

Nyanchoka, L., Tudur-Smith, C., Thu, V. N., Iversen, V., Tricco, A. C., \& Porcher, R. (2019). A scoping review describes methods used to identify, prioritize and display gaps in health research. Journal of Clinical Epidemiology, 109, 99-110. https://doi.org/10.1016/j.jclinepi.2019.01.005 
Research, Society and Development, v. 11, n. 3, e3111326233, 2022

(CC BY 4.0) | ISSN 2525-3409 | DOI: http://dx.doi.org/10.33448/rsd-v11i3.26233

Osorio-de-Castro, C. G. S., Luiza, V. L., Castilho, S. R. de, Oliveira, M. A., \& Jaramillo, N. M. (2014). Assistência Farmacêutica: Gestão e prática para profissionais de saúde. $\left(1^{\circ} \mathrm{ed}\right)$. Rio de Janeiro: Fiocruz.

Schmidt, F. de H., \& Assis, L. R. S. de. (2011). O Estado como cliente: Características das firmas industriais fornecedoras do governo. Boletim Radar: Tecnologia, Produção $e$ Comércio $\quad$ Exterior $\quad$ IPEA. http://repositorio.ipea.gov.br/bitstream/11058/5355/1/Radar_n17_O\%20Estado.pdf

Shamseer, L., Moher, D., Clarke, M., Ghersi, D., Liberati, A., Petticrew, M., Shekelle, P., Stewart, L. A., \& the PRISMA-P Group. (2015). Preferred reporting items for systematic review and meta-analysis protocols (PRISMA-P) 2015: Elaboration and explanation. BMJ, 349(jan02 1), g7647-g7647. https://doi.org/10.1136/bmj.g7647

Silva, L. L. S. da, Lima, A. F. R., Polli, D. A., Razia, P. F. S., Pavão, L. F. A., Cavalcanti, M. A. F. de H., \& Toscano, C. M. (2020). Medidas de distanciamento social para o enfrentamento da COVID-19 no Brasil: Caracterização e análise epidemiológica por estado. Cadernos de Saúde Pública, 36(9), e00185020. https://doi.org/10.1590/0102-311x00185020

Teremetskyi, V., Duliba, Y., Kroitor, V., Korchak, N., \& Makarenko, O. (2021). Corruption and strengthening anti-corruption efforts in healthcare during the pandemic of Covid-19. Medico-Legal Journal, 89(1), 25-28. https://doi.org/10.1177/0025817220971925

Thai, K. V. (2001). Public procurement re-examined. Journal of Public Procurement, 1(1), 9-50. https://doi.org/10.1108/JOPP-01-01-2001B001

Tricco, A. C., Lillie, E., Zarin, W., O'Brien, K. K., Colquhoun, H., Levac, D., et al. (2018). PRISMA Extension for Scoping Reviews (PRISMA-ScR): Checklist and Explanation. Ann Intern Med., 169, 467-73. https://doi.org/10.7326/M18-0850

World Health Organization. (2021). Brazil: WHO Coronavirus Disease (COVID-19) Dashboard With Vaccination Data. https://covid19.who.int 